\title{
Novos táxons sul-americanos de Parmenini e Pteropliini (Coleoptera, Cerambycidae, Lamiinae)
}

\author{
Miguel A. Monné1,2 \& Marcela L. Monné ${ }^{1}$
}

${ }^{1}$ Museu Nacional, Universidade Federal do Rio de Janeiro. Quinta da Boa Vista, São Cristovão, 20940-040 Rio de Janeiro-RJ, Brasil. ${ }^{2}$ Bolsista do CNPq.

\begin{abstract}
New South American taxa in Parmenini and Pteropliini (Coleoptera, Cerambycidae, Lamiinae). The genera Schreiteria Melzer (Parmenini) and Esthlogenopsis Breuning (Pteropliini) and their type species are redescribed and illustrated. Schreiteria colombiana sp. nov. from Colombia and Esthlogenopsis atlantica sp. nov. from Brazil (Bahia, Espírito Santo, Minas Gerais and Rio de Janeiro) are described.

KEYWORDS. Esthlogenopsis; Schreiteria; taxonomy.

RESUMO. Novos táxons sul-americanos de Parmenini e Pteropliini (Coleoptera, Cerambycidae, Lamiinae). Os gêneros Schreiteria Melzer (Parmenini) e Esthlogenopsis Breuning (Pteropliini) e suas espécies-tipo são redescritas e ilustradas. São descritas Schreiteria colombiana sp. nov. da Colômbia e Esthlogenopsis atlantica sp. nov. do Brasil (Bahia, Espírito Santo, Minas Gerais e Rio de Janeiro).
\end{abstract}

PALAVRAS-CHAVE. Esthlogenopsis; Schreiteria; taxonomia.

Os gêneros monotípicos Schreiteria Melzer, 1933 (Parmenini) e Esthlogenopsis Breuning, 1942 (Pteropliini) e suas espécies-tipo são redescritas e uma nova espécie é descrita em cada gênero.

Em decorrência da recente publicação de um catálogo (Monné 2005), as referências citadas sob cada táxon restringemse à descrição original e ao catálogo. As abreviaturas mencionadas no texto correspondem às seguintes instituições: Departamento de Zoologia, Universidade Federal do Paraná (DZUP); Universidade Estadual do Rio de Janeiro (UERJ); Museu Nacional, Universidade Federal do Rio de Janeiro (MNRJ).

Tribo Parmenini

A tribo Parmenini na América do Sul (Monné 2005) está representada por nove gêneros, cinco restritos ao Chile: Cleptonotus Breuning, 1950, Cleptosoma Breuning, 1950, Hoplocleptes Breuning, 1947, Microcleptes Newman, 1840 e Neohoplonotus Monné, 2005; um no Brasil, Plaumanniella Fisher, 1938; na Argentina, Schreiteria Melzer, 1933; no Peru, Tuberolamia Breuning, 1940 e no Equador, Gracililamia Breuning, 1961.

Melzer (1933, 1934) descreveu duas vezes Schreiteria e o localizou provisoriamente na tribo Dorcadionini. Breuning (1950), na revisão dos Parmenini, considerou Schreiteria como pertencente a esta tribo, afirmando que conhecia a espécie apenas pela descrição.

Schreiteria Melzer, 1933

Schreiteria Melzer, 1933: 459; Monné, 2005: 609 (cat.).

Espécie tipo. Schreiteria bruchi Melzer, 1933, por monotipia e designação original.
Fronte ampla, transversa. Tubérculos anteníferos elevados e distantes entre si. Olhos grosseiramente facetados, fortemente emarginados; lobos oculares superiores distantes entre si pelo menos duas vezes a largura de um lobo. Antenas com 11 antenômeros; escapo alongado, cilíndrico, com cerca de $2 / 3$ do comprimento do III e este ligeiramente mais longo que o IV; V$\mathrm{XI}$ curtos e subiguais. Protórax transverso, arredondado aos lados. Pronoto convexo. Cavidades cotilóides anteriores fechadas atrás e médias abertas aos lados. Metasterno estreito, 1/3 mais longo que o mesosterno. Escutelo trapezoidal. Úmeros arredondados. Élitros paralelos, pouco convexos, pelo menos três vezes mais longos que o protórax. Asas membranosas reduzidas ou ausentes. Pernas posteriores $1 / 3$ mais longas que as anteriores; fêmures clavados; mesotarsômero I cerca de 1,5 vezes mais longo que o seguinte e, nas fêmeas, cerca de $1 / 3$ mais longo; metatarsômero I com o dobro do comprimento do seguinte e, nas fêmeas, 1,5 vezes mais longo. Esternitos I-IV subiguais em comprimento; $\mathrm{V}$ ligeiramente mais longo que o IV, acuminado para o ápice.

Discussão. Schreiteria difere dos demais gêneros sulamericanos de Parmenini pelo conjunto de caracteres: protórax transverso e sem tubérculos laterais, élitros pouco convexos e pelo menos três vezes mais longos que o protórax.

Schreiteria bruchi Melzer, 1933

(Fig. 1)

Schreiteria bruchi Melzer, 1933: 460; Monné, 2005: 609 (cat.).

Tegumento castanho-avermelhado. Cabeça com pubescência esbranquiçada; região dorsal posterior com pontos 
grossos e esparsos. Antenas, nos machos, ultrapassam os ápices elitrais no antenômero VII; nas fêmeas, no X; III-V com pubescência castanho-escura exceto na base e em faixa pósmediana, esbranquiçada; VI-XI com pubescência castanhoescura exceto na base esbranquiçada; III, nos machos, com cerca do dobro do comprimento do IV e com projeção aguçada, curva, apical interna; nas fêmeas cerca de 1,5 vezes o IV e com ápice inerme. Protórax, mesosterno e metasterno com pubescência esbranquiçada. Margens anterior e posterior do pronoto com pontos grossos e esparsos. Processo prosternal estreito, cerca da metade do diâmetro da procoxa. Processo mesosternal tão largo quanto o diâmetro da mesocoxa. Élitros, na base, tão largos quanto o bordo posterior do protórax; com diminuto tubérculo centro-basal ornado de pêlos eretos; pubescência esbranquiçada e três faixas longitudinais, uma na epipleura, uma mediana e uma próxima à sutura com pubescência mais concentrada, formando pequenos tufos; ápices acuminados. Asas membranosas ausentes. Fêmures com pubescência esbranquiçada exceto anel castanho-escuro, próximo ao ápice; tíbias com pubescência castanho-escura exceto a base e região mediana, esbranquiçada. Abdome com pubescência esbranquiçada; esternito V com margem apical sinuosa; tergito $\mathrm{V}$ com margem apical arredondada.

Dimensões, em mm, macho/fêmea. Comprimento total, 12,2/ 13,5; comprimento do protórax, 2,1/2,0; maior largura do protórax, 3,4/3,2; comprimento do élitro, 9,8/9,0; largura umeral, $3,8 / 3,5$.

Material examinado. ARGENTINA, Tucumán: Olivos, macho, XII.1933, "en yareta" (MNRJ); Departamento Tafí, "cumbre proximo San José", fêmea, 23.V.1934, "en yareta" (MNRJ).

Comentários. Schreiteria bruchi Melzer, 1933 é conhecida apenas da Provincia de Tucumán, em altitudes que variam de 3000 a 4000 metros. Bruch (1935) publicou a biologia e informou que as larvas se alimentam das partes lenhosas da "yareta", Azorella yareta Hauman (Apiaceae). Schreiteria colombiana sp. nov. também ocorre em altitude e a larva, de acordo com os dados da etiqueta, alimenta-se de Espeletia grandiflora Bonpl. (Asteraceae).

\section{Schreiteria colombiana sp. nov.}

(Fig. 2)

Fêmea. Tegumento castanho-avermelhado. Cabeça com pubescência castanho-clara exceto ao redor dos lobos oculares superiores, esbranquiçada; região dorsal posterior lisa. Antenas ultrapassam os ápices elitrais no antenômero $\mathrm{X}$; pubescência castanho-escura exceto na base, esbranquiçada; antenômero III com cerca de 2/3 do comprimento do IV e sem projeção apical interna. Protórax, mesosterno e metasterno com pubescência esbranquiçada. Pronoto com um par de tubérculos rombos antemedianos; margens anterior e posterior com pontos grossos e esparsos. Processo prosternal estreito, cerca de 1/3 do diâmetro da procoxa. Processo mesosternal cerca da metade do diâmetro da mesocoxa. Élitros, na base, notadamente mais largos que o bordo posterior do protórax; pubescência acinzentada e pequenas manchas arredondadas de pubescência castanho-escura formando fileiras; pontuação grossa, moderadamente densa, granulosa e adensada no terço basal; ápices truncados. Asas membranosas reduzidas. Pernas com pubescência esbranquiçada exceto no terço anterior das tíbias, castanho-escura. Urosternitos com pubescência esbranquiçada; esternito V com margem semicircularmente entalhada; tergito V com margem sinuosa.

Dimensões, em mm, fêmea. Comprimento total, 7,5-9,8; comprimento do protórax, 1,7-2,0; maior largura do protórax, 2,3-2,8; comprimento do élitro, 5,2-6,8; largura umeral, 2,8-3,2.

Material-tipo. Holótipo fêmea, COLÔMBIA, Distrito Capital de Bogotá: Páramo de Monserrate, "bei Bogotá, 3230m, in Espeletia grandiflora", 9.VIII.1968, Fuchs col. (MNRJ). Parátipos: mesmos dados do holótipo, fêmea, 12.IV.1968, 2 fêmeas, 31.V.1968 (MNRJ); Boyacá: Páramo Chita, fêmea, "2 wisch Soatá u. Belén, 3230m, in Espeletia ca. $157 \mathrm{~cm} "$, Fuchs col. (MNRJ).

Discussão. Schreiteria colombiana sp. nov. difere de $S$. bruchi, principalmente, por apresentar os úmeros mais largos que a borda posterior do protórax, ausência de tubérculo centrobasal nos élitros e as asas membranosas reduzidas. Em Schreiteria bruchi, os úmeros são tão largos quanto a borda posterior do protórax, cada élitro apresenta um tubérculo centrobasal e não tem asas membranosas.

\section{Tribo Pteropliini}

\section{Esthlogenopsis Breuning, 1942}

Esthlogenopsis Breuning, 1942: 138; Monné, 2005: 643 (cat.). Espécie tipo. Esthlogenopsis ochreoscutellaris Breuning, 1942 por monotipia e designação original.

Cabeça com pontos grossos e moderadamente densos. Tubérculos anteníferos projetados e divergentes. Olhos grosseiramente facetados; lobos oculares superiores tão distantes entre si quanto 1,5 vezes a largura de um lobo. Genas curtas, cerca de 1/3 do diâmetro do lobo ocular inferior. Antenas filiformes; escapo engrossado, sem cicatriz, cerca de $2 / 3$ do comprimento do antenômero III; V-XI gradualmente decrescentes em comprimento. Protórax quase tão largo quanto longo (sem medir tubérculos laterais), com pontos grossos, profundos e densos; aos lados com um tubérculo acuminado pós-mediano. Cavidades cotilóides anteriores fechadas atrás e, as médias, abertas aos lados. Processo prosternal cerca de 1/3 do diâmetro da procoxa. Processo mesosternal ligeiramente entalhado no ápice, cerca da metade do diâmetro da mesocoxa. Escutelo quadrangular com margem apical truncada. Úmeros arredondados, com pequeno tubérculo aguçado. Élitros sem pêlos eretos, cerca de três vezes mais longos que o protórax; ápices arredondados. Pernas curtas e subiguais; procoxas cônicas; mesocoxas arredondadas; fêmures fusiformes; tíbias delgadas e cilíndricas; metatarsômero I subigual ao seguinte em comprimento. Urosternito $\mathrm{V}$ com margem apical emarginada. 

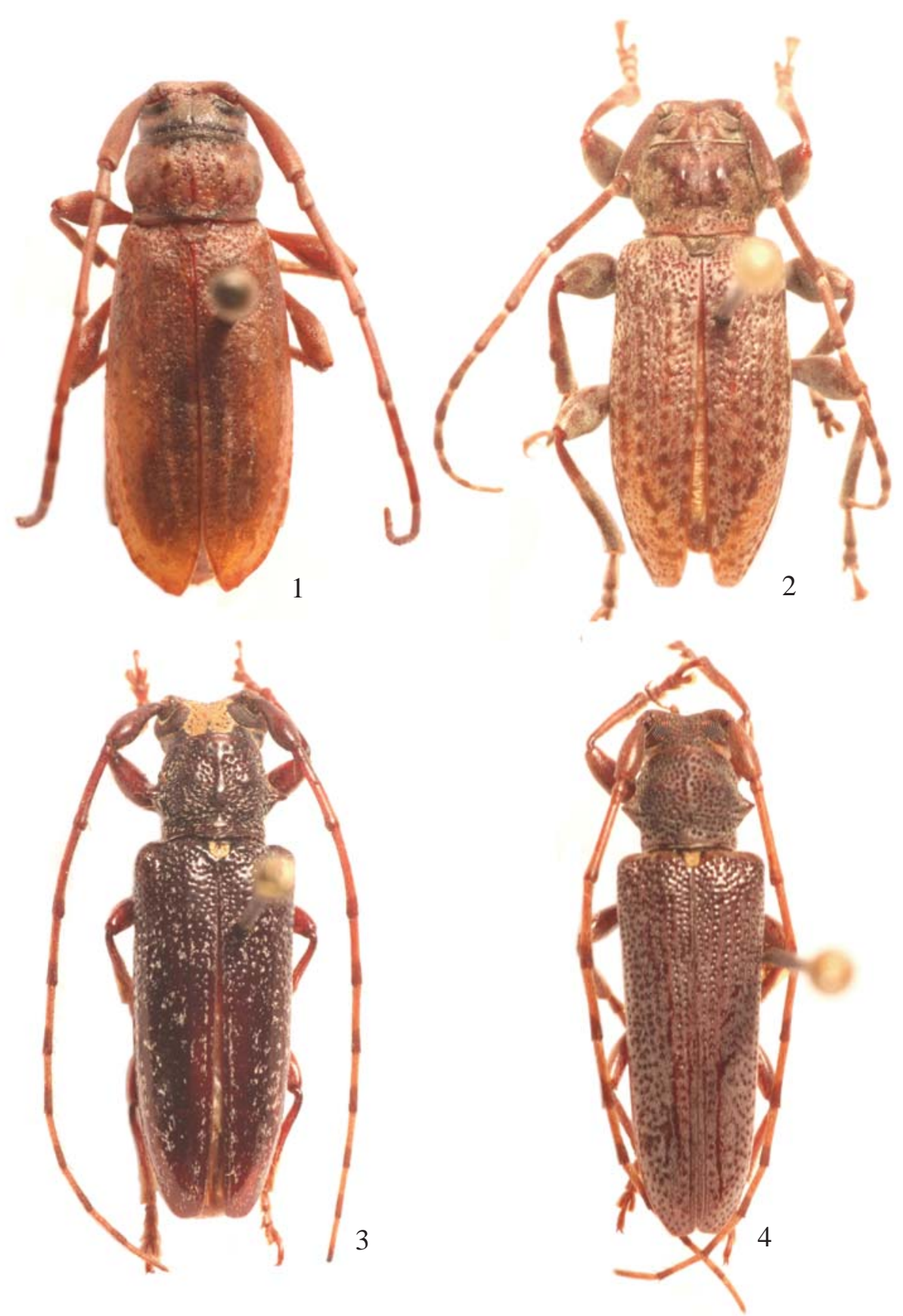

Figs. 1-4. 1, Schreiteria bruchi (Departamento Tafí, Tucumán, Argentina), fêmea, 13,5 mm; 2, S. colombiana sp. nov., holótipo fêmea, 9,8 mm; 3, Esthlogenopsis ochreoscutellaris (Tabatinga, Amazonas, Brasil), macho, 13,4 mm; 4, E. atlantica sp. nov., holótipo macho, 11,0 mm.

Discussão. Entre os gêneros de Pteropliini, Esthlogenopsis assemelha-se a Esthlogena Thomson, 1864 pelo escapo sem cicatriz e o protórax quase tão largo quanto longo, aos lados com tubérculo acuminado pós-mediano. Esthlogenopsis difere de Esthlogena pelo corpo sem pêlos eretos, o escapo engrossado e úmeros com pequeno tubérculo aguçado. Em Esthlogena, o corpo, de maneira geral, é revestido por pêlos longos e eretos, o escapo é cilíndrico e os úmeros não apresentam tubérculos.
Esthlogenopsis ochreoscutellaris Breuning, 1942 (Fig. 3)

Esthlogenopsis ochreoscutellaris Breuning, 1942: 138; Monné, 2005: 643 (cat.).

Tegumento castanho-claro à escuro; antenas castanhoavermelhadas exceto ápice dos antenômeros IV-X, enegrecidos; pernas castanho-avermelhadas. Corpo, de maneira geral, com pilosidade curta, moderadamente esparsa, desuniforme e 
esbranquiçada. Cabeça com pilosidade, que recobre o vértex, curta, densa e amarelada. Antenas com pubescência amarelada; face inferior com fileira de pêlos longos e castanhos; ultrapassam os ápices elitrais no antenômero X; antenômero III tão longo quanto o IV. Pronoto com pontos grossos, profundos e densos exceto faixa mediana longitudinal, lisa. Processo mesosternal tuberculado no ápice. Escutelo recoberto por pilosidade amarelada. Élitros com pontos grossos, rasos e desunifomes, distintamente adensados no terço basal.

Dimensões, em mm, macho. Comprimento total, 8,2-14,5; comprimento do protórax, 1,5-2,5; maior largura do protórax (sem tubérculos), 1,7-2,8; comprimento do élitro, 5,3-10,2; largura umeral, 2,1-4,1.

Descrita de Jataí, Goiás, Brasil (Breuning 1942: 138). Examinamos material proveniente de: BRASIL, Amazonas: Tabatinga, macho, XI.1977, B. Silva col. (MNRJ); Rondônia: Ariquemes, macho, VIII.1980, B. Silva col. (MNRJ); Ouro Preto do Oeste, macho, VIII.1980, B. Silva col. (MNRJ); Mato Grosso: Jacaré, Parque Nacional Xingú, macho, XI.1961, Alvarenga \& Werner col. (MNRJ).

\section{Esthlogenopsis atlantica sp. nov.}

(Fig. 4)

Tegumento vermelho-escuro a castanho-escuro; antenas castanho-alaranjadas, escurecidas nos ápices dos antenômeros III-X; pernas castanho-alaranjadas. Corpo recoberto por pubescência decumbente, uniforme e acinzentada. Antenas com pubescência amarelada; nos machos, ultrapassam os ápices elitrais no antenômero IX e nas fêmeas apenas alcançam os ápices; antenômero III 1/3 mais longo que o IV. Pronoto com um par de tubérculos rombos antemedianos e uma carena longitudinal mediana ligeiramente elevada. Processo mesosternal entalhado no ápice. Escutelo recoberto por pilosidade amarelada. Élitros com pontos grossos e rasos, adensados e ligeiramente organizados em fileiras no terço basal.

Dimensões, em mm, macho/fêmea. Comprimento total, 9,815,2/11,8; comprimento do protórax, 1,7-3,2/1,8; maior largura do protórax (sem tubérculos), 1,9-3,5/2,0; comprimento do élitro, 6,0-10,3/8,0; largura umeral, 2,2-3,7/2,9.
Material-tipo. Holótipo macho, BRASIL, Bahia: Encruzilhada, Estrada Rio-Bahia, km 965, Motel da Divisa, 960m, XI.1971, Seabra \& Roppa col.(MNRJ). Parátipos: mesmos dados do holótipo, 2 machos, fêmea, XI.1972; macho, XI.1970; 4 machos, fêmea, XI.1974 (MNRJ). Espirito Santo: Colatina, macho, X.1970, B. Silva col. (MNRJ); Linhares, 3 machos, XI.1971, B. Silva col., fêmea, XI.1965, macho, fêmea, XI.1967, fêmea, XI.1969, F. M. Oliveira col. (MNRJ); Pedro Canário, macho, XI.1976, E. dos Santos col. (MNRJ). Minas Gerais: Pedra Azul, macho, fêmea, 700m, XI.1971, fêmea, XI.1972, Seabra \& Oliveira col. (MNRJ); Teófilo Otoni, macho, XI.1974, S. P. Nascimento col. (MNRJ). Rio de Janeiro: Rio de Janeiro, Corcovado, macho, 14.I.1959, Alvarenga \& Seabra col., Floresta da Tijuca, fêmea, II.1970, Seabra col. (MNRJ).

Discussão. Esthlogenopsis atlantica sp. nov. é muito semelhante a E. ochreoscutellaris pelo escapo engrossado, protórax com tubérculos laterais, pontuação elitral mais adensada no terço basal e os inconspícuos tubérculos nos úmeros. Esthlogenopsis atlantica sp. nov. difere de E. ochreoscutellaris pelo pronoto com um par de tubérculos antemedianos e pela pubescência do corpo uniforme e, de maneira geral, acinzentada. Em E. ochreoscutellaris, o pronoto não apresenta tubérculos e a pubescência do corpo é esbranquiçada e desuniforme exceto no vértex e escutelo onde é amarela e densa. Vale destacar que E. atlantica ocorre na Floresta Atlântica enquanto E. ochreoscutellaris distribui-se na Amazônia e no Brasil central.

Agradecimentos. Ao Prof. José Ricardo Miras Mermudes (UERJ) pela execução das fotos e à Prof. Solange Napp (DZUP) pelas sugestões e correções ao manuscrito.

\section{REFERÊNCIAS}

Breuning, S. 1942. Novae species Cerambycidarum. XI. Folia Zoologica et Hydrobiologica 11: 113-175.

Breuning, S. 1950. Révision des Parmenini. Longicornia 1: 29-259.

Bruch, C. 1935. Biologia y metamorfosis de un interesante longicórnio: Schreiteria bruchi Melzer (Col., Cerambycidae). Physis 11: 361365.

Melzer, J. 1933. Nota prévia sôbre um longicórnio interessante dos Andes da Argentina. Revista de Entomologia 3: 459-461.

Melzer, J. 1934. Longicórneos americanos, principalmente do Brasil, novos ou pouco conhecidos. Archivos do Instituto Biologico 5: $213-244$

Monné, M. A. 2005. Catalogue of the Cerambycidae (Coleoptera) of the Neotropical Region. Part II. Subfamily Lamiinae. Zootaxa 1023: $1-759$. 